\title{
Analysis of Substance Use and its Relation to the Tax Policy of the Czech Republic
}

\author{
KOLÁŘOVÁ, E., HOMOLA, D., KOLÁŘOVÁ, V., KRAMNÁ, E.
}

Tomas Bata University, Faculty of Management and Economics, Zlín, Czech Republic
Citation | Kolářová, E., Homola, D., Kolárová, V., Kramná, E. (2019). Analysis of Substance Use and its Relation to the Tax Policy of the Czech Republic. Adiktologie, 1911), 27-34; https://doi.org/10.35198/01-2019-001-0003
BACKGROUND: Addictive substances have been part of our lives since historical times. For the Czech Republic, this is especially true of the consumption of cigarettes and alcohol. It has long since been proven that these substances are harmful for the human organism and addiction to such substances has farreaching impacts on the social and economic life of people. On the other hand, revenues to state budgets arising from the taxation of these substances are significant in every country around the world, and to find a balance between the prevention of their use and the revenues of the state is a problem faced by every government. AIM: The aim of this paper is to focus on the consumption of alcohol and cigarettes in the Czech Republic and ascertain its impacts on the revenues of the Czech Republic. METHODS: The sources of data for this research were publicly available from individual ministries of the Czech Republic and from the Czech Statistical Office. Statistical methods were used for the data analysis and interpretation of the findings, including quantitative research, in which basic types of dependency were demonstrated and basic hypotheses were tested. RESULTS: The results have shown that there is a dependency between the number of smokers and excise tax on cigarettes and that there is a dependency between tax revenues from beer and the average wage in the Czech Republic.

CONCLUSIONS: This shows that the amount of excise tax does not affect substance use in the Czech Republic and these prevention policies are not effective in the Czech setting. On the other hand, a single significant increase in the excise tax rate would perhaps help in the area of prevention but it would not benefit the state treasury of the Czech Republic, as the impact of a higher tax rate on state revenues would be cancelled out by a drop in consumption.

\section{Keywords | Tax Policy - Czech Republic - Alcohol - Smoking - Excise Tax}




\section{INTRODUCTION}

The excessive consumption of alcohol and smoking are among the most serious social and economic problems of contemporary society. The level of health of the population is important for the social and economic development of the country; a poor health level can disturb the stability of the entire national community.

Current data from the annual drug report in the Czech Republic show that the consumption of alcohol and tobacco in its population is still high. According to the research result, $2,400,000$ people smoke cigarettes daily, the number of electronic cigarette users continues to grow, approximately 690,000 people drink alcohol daily or almost daily, and only $3.8 \%$ of adults are lifelong teetotallers (Drogy-info.cz, 2016). The 2018 Global Status Report on Alcohol and Health published by the WHO summarises that the absolute per capita consumption of alcohol recorded in the Czech Republic has risen to 14.4 litres per year and more than one fifth of the Czech population smokes. As far as the type of alcoholic beverages consumed is concerned, the most consumed alcoholic beverages were beer, which covers 54\%, spirits (25\%), and wine (21\%). The WHO recommends working with the setting of the price, advertising, and availability of these commodities (WHO, 2018).

Alcohol and nicotine belong among the most widespread legal addictive substances in the world. According to the data of the Czech Statistical Office, it is evident that the trend of alcohol consumption and smoking in the Czech Republic is not favourable. Although the consumption of alcohol and smoking decreased in 2015, the level of consumption began to grow again in the following year (CZSO, 2018).

The Law on the Protection of Health from the Harmful Effects of Addictive Substances came into force in 2017. It could help reduce smoking and alcoholism in the Czech Republic (Zákony pro lidi, 2018). At the multinational level, the World Health Organisation (WHO) is the main engine in the fight against smoking and the consumption of alcohol. One of the important documents in this field is the International Framework Convention on Tobacco Control (FCTC), which was ratified by the Czech Republic in 2012. Its aim is to reduce the negative impacts of tobacco consumption on public health and the economy. One of the measures to reduce tobacco consumption is to implement optimal tobacco taxation and at the same time the government should ensure that there is no illegal trade in tobacco (WHO, 2018).

Europe is the region with the highest alcohol consumption. Because of a combination of a high degree of potential harmfulness and a high rate of widespread use, the application of a pragmatic harm reduction and risk reduction approach to alcohol is necessary. From the economic point of view, the cost of treatment, prevention, research, law enforcement, and lost productivity resulting from alcohol consumption in countries with higher and middle incomes is about $1-3 \%$ of their gross domestic product (Rehm et al., 2009); in the original EU15, it was 1.3\% of GDP in 2003
(Anderson \& Baumberg, 2006). These estimates do not include the associated material costs of individuals and their families. The cost of implementing risk minimisation interventions is simply worth it in the light of the above. Interventions to reduce alcohol-related harm at the structural level most often take the form of legislative measures through laws, decrees, and other regulations. According to Babor et al. (2003), who, on basis of more than 500 alcohol policy studies, assessed the cost-effectiveness of individual strategies, it can be recommended to pay particular attention to taxation, limiting accessibility in the form of age limits for alcohol sales and alcohol testing behind the wheel. Anderson et al. (2009) came to a similar conclusion in their survey study: from the point of view of cost-effectiveness, cost-cutting and accessibility strategies are most advantageous; prohibition of advertising and measures against driving under the influence of alcohol can also be effective under certain circumstances. In September 2011, the European Regional Committee endorsed the "European Action Plan on the Reduction of Harmful Use of Alcohol 2012-2020". On basis of previous European action plans in the area of alcohol, the main objectives and action points of the new Action Plan are aligned with the World Health Organisation Global Alcohol Strategy (WHO, 2011).

Fifty-four years have passed since the ground-breaking report on the harmful effects of smoking cigarettes. Governments are striving to find a balance between trying to reduce tobacco consumption, increasing budget revenues, and regulating tobacco consumption through tax measures. An excise tax on cigarettes is imposed by the vast majority of countries in the world. Cigarette smoking is generally considered harmful and states are interested in reducing it. At the same time, governments are gaining substantial revenues to the state budget from the taxation of cigarettes. The tax component accounts for a significant portion of the retail price of cigarettes, but the amount of excise duty would not have an impact in terms of an increased illicit tobacco trade. Such settings are also being pursued by organisations fighting against smoking.

Six cost-effective measures should be prioritised in comprehensive tobacco control programmes, comprising taxes, smoke-free laws, public information, advertising bans, direct health warnings, and access to treatment. Increasing taxation on tobacco products is the most effective measure; however, the evidence suggests that the best result is achieved when a comprehensive tobacco control policy is implemented (Feliu et al., 2018)

Recommendations aimed at reducing tobacco consumption have been summarised in the MPOWER document, which represents the six main priorities of the effective strategies of the World Health Organisation (Sovinová, \& Czemy, 2013):

1. Monitor tobacco use and prevention policies

2. Protect people from tobacco smoke

3. Offer help in quitting smoking

4. Warn about the dangers of using tobacco 
5. Promote a ban on tobacco advertising and its promotion and sponsorship

6. Increase tobacco taxes

Some of these recommendations are already being implemented in the Czech Republic, particularly within the framework of the implementation of the 2015-2018 Tobacco Control Action Plan and the Harm Reduction Action Plan for 2015-2018. Both of these Action Plans are based on the first strategic objective - Improving public health and reducing health inequalities (Health 2020) - of the National Strategy for Health Protection and Promotion and Disease Prevention.

Tobacco companies have publicly denied for decades that nicotine was addictive. In 2000, Philip Morris became the first tobacco company to publicly state that nicotine is addictive. The tobacco industry avidly promotes new nicotine products, emphasising that nicotine addiction is the key driver of smoking. To improve addiction outcomes, public health authorities should continue expanding and strengthening social and environmental restrictions on cigarette smoking (Jesse Elias et al., 2018).

Since June 2017, there has been a ban on smoking inside restaurants, theatres, and cinemas in the Czech Republic. The norm also introduced a ban on smoking in uncovered parts of public transport stops and the use of electronic cigarettes in hospitals, schools, or shopping centres. It also prohibits the sale of cigarettes in vending machines from which it is possible for children under the age of 18 to buy cigarettes without obstacles (MZCR, 2017).

Taxes are commonly found in every person's life. They can influence us either directly or indirectly in the prices of goods or services. Excise taxes are among the indirect taxes, and the most important of this group of taxes are taxes on mineral oils, since they account for the largest part of the revenues of the state budget. The second most profitable tax in the Czech Republic is that on tobacco products. The excise tax on cigarettes is based on a fixed tax rate part and also on a tax rate calculated as a percentage. The resulting tax is calculated by adding them together. For each packet of cigarettes, at least a minimum excise tax is payable. The rates of excise taxes on tobacco products are very often amended; the data set out in Section 104 of the Excise Tax Act is always in effect. The alcohol tax, more specifically the tax on alcohol and spirits, is the third most profitable excise tax in the Czech Republic. There is a distinction between the alcohol tax on fruit spirits and the tax on alcohol and spirits contained in other products. Spirits distilled from home-grown fruit in small-scale distilleries are taxed at a half rate. The amount of excise tax depends on the alcohol content of the products. The tax revenue from the excise tax on beer does not change much in individual years. The tax rates favour smaller breweries. The tax rate is based on the quantity of beer produced by the brewery, expressed in hectolitres. For all wine other than sparkling wine and semi-sparkling wine, the excise tax rate is zero (Marková, 2018).

\section{DATA AND METHODOLOGY}

The paper focuses on the two main addictive substances which are legally consumed in the Czech Republic. The aim of the research was to analyse the development of the consumption of these substances in relation to tax revenues. The research was carried out in 2018 and primary data was obtained for the years 2007 to 2017. Data relating to tax revenues was obtained from the State Closing Account of the Czech Republic and the respective tax rates were obtained from the tax laws of the relevant years. Data on average wages, average alcohol consumption, and the number of smokers was obtained from the Czech Statistical Office and the Customs Office of the Czech Republic. The SPSS statistical program, which is suitable for the area of finances, was used to test dependencies in order to analyse the impact of the tax rate on cigarette consumption and the number of smokers. The Shapiro-Wilk test was used to determine if the data was normally distributed and the Pearson's correlation coefficient was used to determine the dependencies. We tested the relationship between the number of smokers and the cigarette tax rate and the average wage and the relationship between cigarette consumption per capita and the excise tax on cigarettes. Time series were also subsequently tested in detail.

It can be clearly seen that the most consumed alcoholic beverage in the Czech Republic is definitely beer and that is why we focus on it in our research. The dependency of beer consumption on average wages was tested in order to prove the dependency between average wages and tax revenues from beer consumption.

On the basis of the data obtained, the following hypotheses were stated:

Hypothesis $\mathrm{H}_{1}-$ An increase in the cigarette tax reduces the number of smokers

Hypothesis $\mathrm{H}_{2}-$ An increase in average wages results in an increase in tax revenues from the excise tax from alcohol.

\subsection{Data for tobacco testing}

According to research conducted in the population aged 15-64 in the Czech Republic, we refer to smokers as those who smoke regularly, those who smoke one cigarette a day. and those who smoke, but only irregularly. Primary data was obtained from the Czech Statistical Office, the Customs Office of the Czech Republic, and the respective tax laws. The percentage of taxation for a pack of cigarettes differs on basis of many criteria, so only the minimum rate is stated in Table 1.

In 2018, 28.5\% of the adult population of the Czech Republic were smokers. Compared with 2017 (25.2\%), we recorded an increase of 3.3 percentage points. From the current smokers, more than two thirds (21.1\%) are daily smokers. $24.5 \%$ of men and $17.9 \%$ of women in the Czech Republic 


\begin{tabular}{|c|c|c|c|c|c|}
\hline Year & 2007 & 2008 & 2009 & 2010 & 2011 \\
\hline Smokers \% & 38.2 & 28.2 & 29.2 & 29.3 & 29.1 \\
\hline Minimum rate of tax per piece in CZK & 1.64 & 1.92 & 2.01 & 2.01 & 2.01 \\
\hline Minimum excise tax on tobacco in CZK & 32.80 & 38.40 & 40.20 & 40.20 & 40.20 \\
\hline Average wage in CZK & 20,957 & 22,592 & 23,344 & 23,864 & 24,455 \\
\hline Tax Revenues from Tobacco in Billion CZK & 47.00 & 37.51 & 37.70 & 42.47 & 44.96 \\
\hline Year & 2012 & 2013 & 2014 & 2015 & 2016 \\
\hline Smokers \% & 31.3 & 29.9 & 31.4 & 24.1 & 28.6 \\
\hline Minimum rate of tax per piece in CZK & 2.01 & 2.18 & 2.25 & 2.37 & 2.52 \\
\hline Minimum excise tax in CZK & 40.20 & 43.60 & 45.00 & 47.40 & 50.40 \\
\hline Average wage in CZK & 25,101 & 25,128 & 25,686 & 26,467 & 27,589 \\
\hline Tax Revenues from Tobacco in Billion CZK & 47.00 & 46.82 & 44.70 & 50.86 & 54.40 \\
\hline
\end{tabular}

Table 1 | Development of researched data in the Czech Republic in 2007-2016. Source: Czech Statistical Office, Customs Office, Excise Tax Act

\begin{tabular}{|c|c|c|c|c|c|}
\hline Consumption (litres)/ Tax Revenues in CZK & 2007 & 2008 & 2009 & 2010 & 2011 \\
\hline Total consumption & 185.8 & 183.2 & 177.6 & 170.9 & 168.8 \\
\hline Total revenue in billion CZK & 11.11 & 10.98 & 10.73 & 11.14 & 11.57 \\
\hline Consumption of $\mathbf{4 0} \%$ spirits & 8.2 & 8.1 & 8.2 & 7.0 & 6.9 \\
\hline Pure alcohol and spirits in million CZK & 7.122 & 7.082 & 6.965 & 6.528 & 6.767 \\
\hline Wine consumption & 18.5 & 18.5 & 18.7 & 19.4 & 19.4 \\
\hline Tax on wine in million CZK & 336 & 336 & 326 & 320 & 313 \\
\hline Beer consumption & 159.1 & 156.6 & 150.7 & 144.4 & 142.5 \\
\hline Tax on beer in million CZK & 3.657 & 3.564 & 3.439 & 4.297 & 4.488 \\
\hline Consumption (litres)/Tax Revenues (CZK) & 2012 & 2013 & 2014 & 2015 & 2016 \\
\hline Total consumption & 175.2 & 172.3 & 173.3 & 172.4 & 173.5 \\
\hline Total revenue in billion CZK & 10.55 & 11.18 & 11.7 & 12.4 & 12.2 \\
\hline Consumption of $40 \%$ spirits & 6.7 & 6.5 & 6.7 & 6.9 & 7.0 \\
\hline Pure alcohol and spirits in million CZK & 6.510 & 6.382 & 6.754 & 7.132 & 7.206 \\
\hline Wine consumption & 19.8 & 18.8 & 19.5 & 18.9 & 19.6 \\
\hline Tax on wine in million CZK & 321 & 284 & 295 & 321 & 358 \\
\hline Beer consumption & 148.6 & 147.0 & 147.0 & 146.6 & 146.9 \\
\hline Tax on beer in million CZK & 4.656 & 4.516 & 4.593 & 4.709 & 4.605 \\
\hline
\end{tabular}

Table 2 | Consumption of alcoholic beverages per capita in the Czech Republic and tax revenues from alcoholic beverages. Source: Czech Statistical Office, Customs Office, State Closing Account of the Czech Republic

smoke daily. From the long-term point of view, it can be stated that despite the isolated annual variations, a decrease in the prevalence of smoking can be observed in the years that were monitored, starting from 2012, to 2018.

\subsection{Data for Alcohol testing}

According to the World Health Organisation, Europe is the region with the highest alcohol consumption. Risky use patterns make alcohol one of the most harmful psychoactive substances. (Table 2.)

Regular and frequent drinking, i.e. drinking daily or every other day, was reported by $16.7 \%$ of respondents in 2018 , which is three percentage points more than in 2016. For men, the incidence of frequent drinking (in 2018) was $25.6 \%$, for women $8.1 \%$. Drinking alcoholic beverages at least once a week was reported by $49 \%$ of men in 2018 (46\% in 2016 ) and $27 \%$ of women (22\% in 2016). Given the confidence intervals, the differences in frequent drinking from 2012 to 2018 cannot be interpreted as an indication of a significant shift towards more frequent alcohol consumption. On the contrary, it seems to be an unchangeable and stable consumption characteristic.

\section{RESULTS AND DISCUSSION}

The number of smokers has not changed significantly in the past ten years, even though some fluctuations can be identified, such as between the years 2007 and 2008, and this was 
also confirmed by the State Health Institute of the Czech Republic (MZCR, 2017). This development in the Czech Republic follows the development in other countries of Western Europe. As for the current development, in 2017, the number of smokers dropped to $25.2 \%$. The Czech population mainly smokes cigarettes. The share of other tobacco products intended for smoking is negligible. Tobacco products other than cigarettes include pipes, cigars, and hookahs.

Consumer prices for tobacco have increased steadily since 1989 (excluding stagnation in 2003). A dramatic rise in prices was recorded in 1991 because of the decentralisation of the economy. A substantial increase in prices was recorded in 1993 when the new tax system entered into force, and VAT and excise taxes started to affect the development of tobacco prices.

The highest year-on-year increase in cigarette consumption was in 1990. Cigarette consumption culminated in 1997, when an average smoker consumed 2,354 cigarettes a year; this amount dropped to 1,852 cigarettes a year later as a result of an increase in prices; in 2001, cigarette consumption fell to a minimum of 1,664 cigarettes a year. With accession to the EU and the related increase in excise taxes, the rise in cigarette consumption began to slow down gradually. In 2007, the Czech government approved an increase in the excise tax. As a result of high cigarette prices, cigarette consumption decreased between 2008 and 2013, but not significantly. Smokers smoked 12.3 cigarettes a day in 2017. In general, the number of smokers in the Czech Republic has remained fairly stable in the time frame that was monitored. The number of smokers in the Czech Republic dropped by 3.5 per cent from 2016 to 2017. About five per cent more people also want to quit smoking. These results are taken from a survey by the State Health Institute, which monitors smoking in the population every year (MZCR, 2017). (Figure 1.)
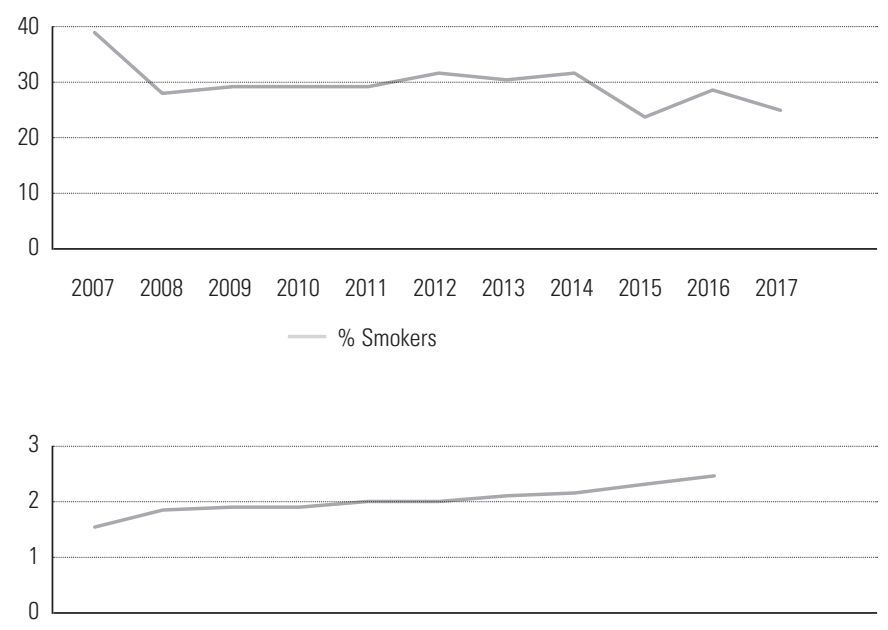

$\begin{array}{lllllllllll}2007 & 2008 & 2009 & 2010 & 2011 & 2012 & 2013 & 2014 & 2015 & 2016 & 2017\end{array}$

- Minimum rate of the excise tax per cigarette

Figure 1 | Development of smoking in the Czech Republic between 2007 and 2016. Source: original research
A visual analysis of the graphs of the course of the time series of the values that were monitored would be too subjective and there would be a high probability that the different users would evaluate dependencies differently, so the charts are included for presentation purposes only. We have used a statistical program to test the dependencies.

From the statistical data it can be concluded that:

- With regard to the percentage of smokers, we are unable to say whether it has increased or decreased since 2007;

- The minimum rate of tax per cigarette increased by 56.5 per cent between 2007 and 2016;

- The minimum excise tax increased by 53.6 per cent between 2007 and 2016;

- Tax revenues from tobacco increased by 31.6 per cent between 2007 and 2016.

We tested the following dependencies in the SPSS statistical program:

- Number of smokers to cigarette tax rate - there is a weak dependency;

- Number of smokers to the average wage - there is no statistically significant dependency;

- Consumption of cigarettes per capita to tax revenues there is no statistically significant dependency;

- Consumption of cigarettes per capita to excise tax on a packet of cigarettes - there is a dependency;

- Tax rate on cigarettes to tax revenues - there is no statistically significant dependency.

The relationship between the number of smokers and the cigarette tax rate shows a dependency; however, R2 is too low (only 0.461). This means that an increase in the excise tax causes the number of smokers to decrease, but only a little, and in some years it does not decrease at all. Even though the excise tax on cigarettes increases every year, the percentage of smokers remains basically the same throughout the years. This means these prevention policies are not very effective in terms of their impact on smokers in the Czech Republic. A single significant increase in the tax rate would not benefit the state treasury. The impact of a higher tax rate on state revenues would be cancelled out by a decrease in consumption.

\subsection{Alcohol}

Alcohol revenues represent the third largest source of revenue from excise taxes in the Czech Republic. It can be clearly seen from the data above that the total consumption of alcohol in the Czech Republic has remained fairly stable for the past 10 years. In our research, we focused on beer consumption. There was a slight decrease in the consumption of beer and spirits after 2009 but it was compensated for by an increase in the consumption of wine in recent years. The tax rate on beer has increased significantly since 2009 , when the standard rate was increased from CZK 24/hl. to CZK 32/hl. (Figures 2 and 3.) 




Figure 2 | Alcohol consumption in the Czech Republic. Source: original research



Figure $\mathbf{3}$ | Tax revenues from alcohol in the Czech Republic. Source: original research

A 26-year survey, called Global Burden of Disease, involving several thousand individuals between the ages of 15 and 95 in a total of 195 countries, examined the impacts of the amount of alcohol consumed on the health of the respondents who were monitored. When the final analysis finally arrived after years of experimentation, it was clearly shown that those who consume alcohol, even to a lesser extent, have an increased risk of cancer. Negative impacts of alcohol are very probable for one fifth of the Czech adult population. These facts emerged from a survey of the State Health Institute in 2014. (GBD Alcohol Collaborators, 2018)

To show the development of the consumption of alcohol beverages and the related tax revenues more clearly, we included the figures above. The most significant factors in the area of tax revenues appear to be spirits and pure alcohol, but that does not mean that spirits generate higher revenues than, for example, beer. This category includes not only spirits but also pure alcohols which are used in the industrial processing of other alcoholic beverages and are not used for personal consumption. Excise tax revenues from wine are generally lower than those from other categories, as there are significant tax exemptions for wine. There is no excise duty on still wine.

From the statistical data it can be concluded that:

- The total consumption of alcoholic beverages decreased from 2007 to 2016, but the lowest consumption was in 2011; 
- With regard to the total tax revenue from the consumption of alcoholic beverages, we are unable to say whether the trend is increasing or decreasing. Until 2009, total tax revenues decreased and from that year they increased, with the exception of 2012;

- Beer consumption decreased until the year 2011, and from 2012, the level of consumption remained basically unchanged;

- The tax revenues from beer declined until 2009, but since 2010, when the standard tax rate increased by 33.3 per cent, tax revenues from beer have increased by 28.6 per cent on average.

We tested the following dependencies in the SPSS statistical program:

- Tax revenues from beer to the average wage - there is a dependency;

- Consumption of beer to the average wage - there is a weak dependency;

- Consumption of pure alcohol and spirits to time - there is a dependency;

- Consumption of alcohol to the average wage - there is a weak dependency.

Other dependencies were insignificant.

The dependency between beer consumption and excise tax revenues from beer was identified as R2 is 0.680. A further investigation is recommended for this dependency. That means that tax revenues from beer increase in parallel with the increase in the average wages in the Czech Republic. As the tax rate has not changed at all since 2010, it can be said that the increase in tax revenues is due to an increase in the amount of beer consumed in the Czech Republic, which means that with increasing wages people spend more on beer.

\section{CONCLUSIONS}

In our research on cigarette consumption, we have confirmed that there is only a weak dependency between the number of smokers and the cigarette tax rate; $\mathrm{R} 2$ is very low (only 0.461). This means that an increase in the excise tax causes the number of smokers to decrease, but only a little, and in some years, it does not decrease at all. Neither did we identify a statistically significant dependency between the per capita consumption of cigarettes and tax revenues or between the tax rate on cigarettes and tax revenues. Even though the excise tax on cigarettes increases every year, the percentage of smokers remains basically the same throughout the years. This means the prevention policies are not very effective in terms of their impact on smokers in the Czech Republic. Neither would a one-off significant increase in the tax rate benefit the state treasury. The impact of the higher tax rate on state revenues would be cancelled out by a decrease in consumption.
The Institute for Health Economics and Technology Assessment (iHETA) dealt with the relationship between cigarette prices and consumption. From our analysis it is clear that the price of cigarettes depends on the standard rate of cigarette tax, as the cigarette tax accounts for more than $70 \%$ of the price of cigarettes in the Czech Republic. In our research, we found that there is a weak dependency between the tax on cigarettes and the number of smokers, but the dependency is very low. With this, Hypothesis $\mathrm{H}_{1}$ cannot be confirmed.

One of the basic tools of economics is to examine the demand. The demand research is associated with the price elasticity of the demand, which shows how the quantity that is demanded will change depending on the price of certain goods - in our case cigarettes - with the other factors unchanged. In a meta-analysis, Gallet and List (2003) summarised the results of research on the demand for cigarettes, with an impressive number of 523 articles summarised in their study. In terms of short-term price elasticity, the median of the studies examined $(\mathrm{n}=368)$ is 00.40 and long-term elasticity is $00.44(\mathrm{n}=155)$; thus, a price increase of $1 \%$ will lead to a decrease in demand by $0.4 \%$ in the short term and $0.44 \%$ in the long term. Mlčoch and Doležal (2014) concluded in their research that adults are $16 \%$ less elastic in their demand, but young adults are $13 \%$ more elastic, and teenagers are even $89 \%$ more elastic than adults. This shows that young people, in particular, are much more responsive to price changes than adults are, and the price discourages them from smoking - in descriptive statistics, the median price elasticity of teenagers was -1.46 ( $n=8)$. Chaloupka et al. (2012) similarly claim that the price response is two to three times greater for young people than for older people, so a higher price may discourage these smokers and consequently not create a dependency on tobacco. We did not examine the relationship between the number of smokers in the younger population and the level of cigarette taxes, but it would be an interesting continuation of our research. The study by Decker and Schwartz (2000) points to significant cross-links between cigarette and alcohol consumption. More specifically, an increase in the price of alcohol leads to a reduction in alcohol consumption, as well as a reduction in tobacco consumption. Conversely, an increase in the price of cigarettes leads to a reduction in cigarette consumption but an increase in alcohol consumption, which may indicate a shift from a more expensive drug to a cheaper one.

In our research on alcohol consumption, we have confirmed that tax revenues from beer are dependent on the average wage and also that the consumption of beer is dependent on the average wage. The dependency between beer consumption and excise tax revenues from beer had R2 amounting to 0.680. A further investigation is recommended for this dependency, as tax revenues from beer increase in parallel with the increase in the average wages in the Czech Republic. As the tax rate has not changed at all since 2010, it can be said that the increase in tax revenues is due to an increase in the amount of beer consumed in the Czech Republic, which means that with increasing wages people spend more on beer. 
Beer is the most consumed alcoholic beverage in the Czech Republic and we also focused on it in our research. Increasing the minimum tax rate on beer by one unit will increase tax revenues from beer by CZK 0.193 billion. An increase in time by one unit (i.e. one year) will increase the tax revenues from beer by CZK 0.426 billion. This proves Hypothesis $\mathrm{H}_{2}$. It is also in line with similar research studies conducted on this topic.

This article provides a clear presentation of valid existing data in one paper and may serve as a summary of data about alcohol and cigarette consumption and existing relations in the Czech Republic. However, this paper is limited by the fact that it was oriented in general toward the consumption of alcoholic beverages and of cigarettes and we did not focus on a particular group of consumers (such as young people, or women), as this would enable a better comparison with other research studies and could show other interesting results. However, this still remains an opportunity for future research.
The consumption of addictive substances, and for the Czech Republic the consumption of beer and smoking cigarettes, in particular, can be considered a deeply rooted and hard-tochange custom. This leads us to the conclusion that, regarding the main WHO priorities, Priority No. 6, increasing the tobacco tax, has little or no effect in the Czech setting. As far as future developments are concerned, we have already stated that a one-off significant increase in the excise tax rate would maybe help in the prevention area, but it would not benefit the state treasury of the Czech Republic, as the impact of a higher tax rate on state revenues would be cancelled out by a drop in consumption. For the Czech Republic it would be better to focus on other priorities, such as Priority No. 5, promoting a ban on tobacco advertising and its promotion and sponsorship, and Priority No. 1, monitoring tobacco use and prevention policies, e.g. targeting prospective substance users and protecting them from the harmful effects of addiction. This could be done through education from a young age and it could result in a more significant decrease in the number of smokers and people dependent on alcohol in the future.
Authors' contribution: Eva Kolářová and David Homola designed the study and proposed the study design. Eva Kolářová performed the statistical analysis; David Homola participated in the interpretation of the data and the preparation of the manuscript. Vendula Kolárová was in charge of the collection of the data necessary for the statistical analysis. Eva Kramná was responsible for the literature review and the summary of related work and for the drafting of the introduction to the article. All the authors contributed to the article and approved the final version of the manuscript.

Declaration of interest: There is no conflict of interest involved in this research.

\section{REFERENCES}

Anderson, P., \& Baumberg, B. (2006). Alcohol in Europe: A public health perspective. A report for the European Commission. London: Institute of Alcohol Studies.

Anderson, P., Chisholm, D., \& Fuhr, D. C. (2009). Alcohol and Global Health 2: Effectiveness and cost-effectiveness of policies and programmes to reduce the harm caused by alcohol. London: Lancet. Jun 27;373(9682):2234-46. doi: 10.1016/S0140-6736(09)60744-3.

Babor, T. F., Caetano, R., Casswell, S., Edwards, G., Giesbrecht, N., Graham, K., et al. (2003). Alcohol: No Ordinary Commodity. Research and Public Policy. Oxford: Oxford University Press.

Decker, S. L., \& Schwartz, E., A. (2014). Cigarettes and alcohol: substitutes or complements? NBER working paper n. 7535, Available from: http://www.nber.org/papers/w7535

Drogy-info, (2016). Výroční zpráva o stavu ve věcech drog v České republice v roce 2016. Available from: <https://www.drogy-info.cz/data/obj_ files/32732/786/VZ_2016_drogova_situace_v_CR.pdf>

Elias, J., Hendlin, H. Y., \& Ling, P. L. (2018). Public versus internal conception of addiction: An Analysis of internal Philip Morris documents. PLoS Medicine. May 1;15(5):e1002562. doi: 10.1371/journal.pmed.1002562

Feliu, A., Filippidis, F., Joossens, L., Fong, G. T., Vardavas, I. C., Baena, A., Castellano, Y., Martínez, C., \& Fernández, E. (2018). Impact of tobacco control policies on smoking prevalence and quit ratios in 27 European Union countries from 2006 to 2014. Tobacco Control. Jan; 28(1):101-109. doi: 10.1136/ tobaccocontrol-2017-054119.

Gallet, A. C., \& List, A. J. (2003). Cigarettte demand: a meta-analysis of elasticities. Health Economics 12, 821-835. http://dx.doi.org/doi: 10.1002/hec.765

Gallus, S. et al. (2006). Price and cigarette consumption in Europe. Tobacco Control 15, 114-119. http://dx.doi.org/doi: 10.1136/tc.2005.012468
GBD Alcohol Collaborators (2018). Alcohol use and burden for 195 countries and territories, 1990-2016: a systematic analysis for the Global Burden of Disease Study 2016. Available from: https://www.thelancet.com/action/ showPdf?pii=S0140-6736\%2818\%2931310-2. http://dx.doi.org/doi: 10.1016/S0140-6736(18)31310-2

Chaloupka, F. J. (2012). Tobacco taxes as a tobacco control strategy. Tobacco Control 21, 172-180. http://dx.doi.org/doi: 10.1136/tobaccocontrol-2011-050417

Marková, H. (2018). Zákon č. 353/2003 Sb. - Zákon o spotřebních daních. Praha: Grada.

Mlčoch, T., \& Doležal, T. (2014). Jaký je vztah mezi cenou a jejich spotřebou. IHETA. Available from: http://www.iheta.org/ext/publication/files/vzath\%20 mezi\%20cenou\%20c.\%20a\%20jejich\%20spot\%C5\%99ebou_final.pdf

MZČR. (2017). Předpis č. 65/2017 Sb. - Zákon o ochraně zdraví před škodlivými účinky návykových látek. Praha: Sagit.

Rehm, J., Mathers, C., Popova, S., Thavorncharoensap, M., Teerawattananon, Y., \& Patra, J. (2009). Alcohol and Global Health 1: Global burden of disease and injury and economic cost attributable to alcohol use and alcohol-use disorders. London: Lancet. Jun 27; 373(9682):2223-33. doi: 10.1016/S0140-6736(09)60746-7

Sovinová, H., \& Czemy, L. (2013). Užívání tabáku a alkoholu v České republice 2012. Available from: http://www.szu.cz/uploads/documents/czzp/zavislosti/ Uzivani_tabaku_a_alkoholu_v_Ceske_republice_2012.pdf

World Health Organisation. (2011). European action plan to reduce the harmful use of alcohol 2012-2020. Available from: https://www.stap.nl/en/home/ european-alcohol-policy.html

World Health Organisation. (2018). Global status report on alcohol and health 2018. Available from: http://www.who.int/substance_abuse/publications/ global_alcohol_report/gsr_2018/en/.

Zákony pro lidi.cz. (2018). Zákon č. 65/2017 Zákon o ochraně zdraví prè škodlivými účinky návykových látek. Available from: https://www.zakonyprolidi.cz/cs/2017-65 


\title{
The first University E-learning Study Programme Based on the Adaption of the EUPC: Portuguese Implementation Study
}

\author{
HENRIQUES, S. ${ }^{1}$, BURKHART, G. ${ }^{2}$, MIOVSKÝ, M. ${ }^{3}$
}

1 | University Institute of Lisbon (ISCTE-IUL)/Centre for Research and Studies in Sociology (CIES-IUL) and Aberta University, Portugal

2 | Public Health Unit, European Monitoring Centre for Drugs and Drug Addiction (EMCDDA), Lisbon, Portugal

3| Charles University, First Faculty of Medicine, Department of Addictology, Prague, Czech Republic
Citation | Henriques, S., Burkhart, G., Miovský, M. (2019). The first University E-learning Study Programme Based on the Adaption of the EUPC: Portuguese Implementation Study. Adiktologie, 19(1), 35-41;

https://doi.org/10.35198/01-2019-001-0004
BACKGROUND: The training curriculum has been developed by a European project (UPC-Adapt) cofunded by the European Commission. Eleven partners adapted the Universal Prevention Curriculum to suit the European context. AIMS: The aims of the implementation study were to adapt the EUPC into a standardised university course delivered by distance learning by Universidade Aberta (UAb) and develop a process evaluation study focused on this adaptation process. METHODS: The methodology was inspired by the WHO guidelines for the evaluation of prevention and treatment programmes and combined with qualitative research strategies and methods (observation and qualitative content analysis). PARTICIPANTS: It features distance learning, without geographical borders or physical barriers, which is particularly important for prevention professionals working in the far-flung
Portuguese-speaking environment. RESULTS: Enrolment has been difficult, probably for three reasons: i) people tend to believe that they know everything about prevention, ii) the prevention of substance use might be too narrow a field, and iii) there is no perceived need for a specific qualification in order to do prevention work in Portugal. CONCLUSIONS: EMCDDA staff with proficiency in Portuguese had access to the training course and followed the development of the e-activities and the interaction within the virtual community as part of the evaluation protocol. The course represents the first real e-learning-based university adaptation running in a standard regime in Europe, and UAb (Portugal) has joined Charles University (Prague) in making effective use of programmes and materials based on the original UPC curricula in the university context.

\section{Keywords | EUPC - University Implementation - Prevention Education and Workforce Training - Distance} Learning Education 


\section{INTRODUCTION - IMPROVING AND SUPPORTING THE PREVENTION WORKFORCE}

Some years ago, the European Union realised how important it was to pay more attention to the development of a well-developed prevention workforce. In a Council Decision of September 2015 it demanded from member states that "those developing prevention interventions have competencies and expertise on prevention principles, theories and practice, and are trained and/or specialised professionals who have the support of public institutions (education, health and social services) or work for accredited or recognised institutions or NGOs" (Council of the European Union, 2015: 4). The aim is clear: European countries should invest more in the training of professionals and in better accreditation of the work of NGOs in the prevention field, in order to reduce the number of children that are exposed to the work of un-, semi-, or self-trained prevention providers. It is also an indirect acknowledgement that prevention can be harmful if applied incorrectly.

There is no consolidated routine data collection about the training background and training level of the prevention workforce in Europe. Professionals working in prevention have different training backgrounds, including those in social work, psychology, sociology, and the health sciences. Often, they have previously worked in addiction treatment. Depending on the origins of their training, they might have the respective professional bias: during previous prevention training experiences in Europe it emerged that regulation may be perceived as "prohibition" or changing norms as "fascism", while in some countries evaluation is perceived as "unnecessary" and the evidence of prevention sciences as non-existent. Choice architecture and other environmental approaches are denounced as "manipulation", and indicated prevention as "medicalisation".

Only one recent European study (Ostaszewski et al., 2018), in which senior prevention professionals were asked to rate and describe the prevention proficiency of their colleagues, provides some insight into the level of training of the workforce in Europe. Senior professionals seem to be highly knowledgeable about basic research, programme design, developmental timing, trial design, evaluation, and community collaboration, i.e. traditional prevention skills, but less so about advocacy. In all areas of prevention work there were significant gaps, especially in advocacy, funding, management, and prevention programme development. In recent history we can also find an example of an original European study focusing on learning outcomes (knowledge, skills, and competencies) for prevention professionals which was followed by a small local evaluation study on 100 volunteers representing different professions participating in school prevention programmes (Charvát et al., 2012).

One key finding is that prevention training occurs within practice settings and not during any formal education. Apparently - with the exception of a PhD course in Croatia, a Master's course in Austria, and an online Master's course in Spain dedicated exclusively to prevention - the European prevention workforce currently develops its professional expertise in an informal way, as on-the-job training, because virtually no institution grants degrees specifically in the field of prevention science. Some argue that all education programmes for professionals who work with young people should include prevention science, evidence-based practice (Catalano et al., 2012), and special training for programme implementers. However, such proposals have not led to the development of specific activities. A recent study looking into an addiction-specific university degree study programme (Pavlovská et al., 2017) showed how underestimated prevention science is in this specific academic context. It identified a total of 34 academic study programmes provided by 25 European universities, with only six of these covering the group of study subjects that focus specifically on prevention science. The integration of prevention science into the curricula of specialised academic programmes designed to train addiction professionals is a very rare phenomenon at present. Nevertheless, there are some pioneering efforts, programmes which integrate both prevention science theory and prevention-specific training and practice (e.g. Miovský et al., 2016).

\subsection{European Prevention Curriculum}

In the light of this scenario, a consortium of European prevention scientists has, in an EU-funded project (UPC-Adapt), adapted, condensed, and re-edited what were originally the nine weeks of the Universal Prevention Curriculum coordinator series into a shorter introductory version for Europe, the EUPC. This key decision was made in the context of growing worldwide interest in quality standards and policy. A movement towards developing workforce quality standards can be observed. COPOLAD (Cooperation Programme between Latin America, the Caribbean and the European Union on Drugs Policies) published (in 2016) an integrated perspective on the workforce and in Europe we can find this perspective in the European Drug Prevention Quality Standards - EDPQS (Brotherhood et al., 2013).

Education and training are a fundamental part of quality policy. It is possible to identify specific components and recommendations strengthening the workforce and emphasising the quality of theoretical and practical training and education for prevention professionals. The first international standards (e.g. EDPQS, CICAD - the Inter-American Drug Abuse Control Commission, and CCSA - the China Communication Standards Association) and specifically formulated rules and recommendations focused on the workforce have been developed (Burkhart, 2015). In some countries, the first specific activities have encountered major complications in relation to interdisciplinarity, which is a distinctive attribute of modern prevention. A single disciplinary perspective in prevention (typically sociological, psychological, medical, etc.) is not appropriate or sufficient for real practice. On the other hand, an interdisciplinary approach implies a number of practical difficulties for prevention training and education programmes, e.g. in terms of the practical 
assessment and evaluation of the knowledge, skills, and competencies of teachers, psychologists, GPs, or law enforcement officers (Charvát et al., 2012). This challenging issue helps to accelerate international debate and process networking between universities, training institutes, and other relevant international agencies and bodies (e.g. UNODC - the United Nations Office on Drugs and Crime, CICAD, etc.) with regard to sharing and exchanging experience, quality standards, and developing specific platforms such as ICUDDR (the International Consortium of Universities on Drug Demand Reduction) or international societies such as the EUSPR (the European Society of Prevention Research).

The EUPC is a European curriculum developed for use in prevention training for decision- and policy-makers. The primary goal of the EUPC training is to reduce the health, social, and economic problems associated with substance use by building international prevention capacity through the expansion of the European professional prevention workforce.

This training curriculum has been developed by a European project titled UPC-Adapt, which was co-funded by the European Commission, as mentioned above. Eleven partners from nine European countries cooperated in the project and adapted the Universal Prevention Curriculum (UPC) to suit the European context. The UPC was originally developed by Applied Prevention Science International (APSI) with funding from the US Department of State for the Colombo Plan Drug Advisory Programme. The adaptation process was based on the guidelines of the European Prevention Standards Partnership on the adaptation and dissemination of quality standards in different contexts (EDPQS Toolkit 4¹), which describe how to adapt it. Details of the methodology used and the countries involved in the project are provided in Annex 1. The European curriculum is shorter and more accessible than the original UPC. It can be delivered in five days, unlike the original UPC, which requires up to nine weeks of training. The EUPC can be delivered in different ways. There is an online introductory training course, a module for inclusion in prevention training carried out in academic settings, and a training module for decision-, opinion-, and policy-makers. The structure of the training for the last two modules uses a cascade 'training of trainers' approach whereby trained trainers can disseminate the training further.

\subsection{Overview of Portuguese prevention policy - training needs}

The drugs strategy of the European Union (2013-2020) provides a framework for coordinated responses to drug problems in Europe. At a country level, there are national drug strategies with specific budgetary frameworks and action plans. In Portugal SICAD (Serviço de Intervenção nos Comportamentos Aditivos e nas Dependências) is the governmental institute for drugs and addictions and has the mission of promoting the reduction of psychoactive substance use, the

1| http://prevention-standards.eu/toolkit-4/ prevention of addictive behaviours, and the reduction of dependencies. ${ }^{2}$ SICAD is a body of the Ministry of Health and has the responsibility for the National Plan for Reducing Addictive Behaviours and Dependencies (2013-2020) and its conception, accomplishment, and evaluation.

The interventions run by SICAD are divided into five main dimensions: prevention, harm reduction, treatment, reintegration, and dissuasion. The prevention responses of SICAD are partly covered under the Operational Programme for Integrated Responses (PORI), as well as other programmes and projects developed in coordination with governmental and non-governmental and national and international partners. PORI is a programme with national coverage and integrated activity in the sphere of addictions and dependencies, which seeks to enhance the available synergies either through the development of strategies for conducting diagnoses to justify intervention or through the implementation of the Integrated Responses Programme (PRI). PRI is a specific intervention programme that integrates interdisciplinary and multi-sector responses with some types of intervention (prevention, deterrence, risk reduction and harm reduction, treatment, and rehabilitation) following the results of territory diagnosis as priorities.

Underpinned by the need for interventions in addictive behaviours and dependencies, the National Plan for Reducing Addictive Behaviours and Dependencies aims to guarantee approaches, models, requirements, and practices based on innovation and sustainability, supported by evidence and assuring the empowerment and continuous training of professionals and other agents (SICAD, 2013). Adopting better technical and scientific referents, this Plan clearly identifies training needs for the diverse professionals working with addictive behaviours and dependencies - prevention professionals, but also other professionals from the health, social, judicial, educational, and police services. All these professionals need to develop their competences for better interventions.

The National Plan for Reducing Addictive Behaviours and Dependencies defines better interventions as those based on knowledge and scientific evidence, allowing the qualitative evolution of preventive approaches and their effective adjustment and supporting decision-making processes (SICAD, 2013). These must be supported by training as a global and continuous process that fosters the empowerment of the staff and their professional qualifications to perform interventions. Training for prevention professionals must develop skills which they will find useful in pursuing health promotion, in adjusting to the different needs of different groups, and in responding to the specific demands of a wide range of clients. The Plan underlines the relevance of international cooperation networks for working with a complex phenomenon such as addictive behaviours and dependencies, whether they involve psychoactive substances, gambling, or technologies, in different contexts and life cycle stages (SICAD, 2013). 


\subsection{Aims}

According to EUPC, the goals of prevention are the healthy and safe development of children and young people and also the avoidance of the progression of risk behaviours and substance use problems. In order to develop the prevention workforce according to European guidelines, a training course was developed which was based on the EUPC and adapted to the Portuguese context and its professionals.

In this paper we present and discuss a study about the adaptation and implementation of the EUPC into a standardised university online course at Universidade Aberta (UAb). The aims of this study were: i) to describe the adaptation and implementation process; ii) to provide evidence from the evaluation of this process that was conducted, and iii) as this is the first e-learning study programme delivered in Portuguese, to contribute with its results to new strategies in the field of the development of the prevention workforce.

\section{METHODOLOGY}

The methodological framework was built on the principles of a qualitative evaluation study (Patton, 1990) implemented in educational research (Borg \& Gall, 1989). The team drew inspiration from the multifaceted WHO approach to the evaluation of drug prevention and treatment interventions (WHO, 2000a and 2000b). With this as the basis we focused on content and on the resources needed to support strategic activities to identify the strengths and weaknesses of the implementation.

The data collection process covered an array of field records (internal team reports, observation records, personal records made on an ongoing basis by the team leader, internal student evaluations, etc.). The qualitative content analysis was based on coding and involved a hierarchical sorting method (Miles \& Huberman, 1994).

The study presented in this paper has two analytical levels. The first one is focused on the implementation process, i.e. the institutional framework, the particular steps required by the adaptation of the EUPC to the needs of Portuguese prevention professionals and to the technical and pedagogical demands of distance learning, and on the assessment of the trainees. This process was developed from November 2017 to July 2018. The second level is focused on the evaluation study conducted by a member of ICUDDR, a member of the EMCDDA, and the coordinator of the training course. The evaluation of the implementation was conducted in 2018 and cuts across all the items involved in the process that have just been mentioned.

\section{RESULTS - IMPLEMENTATION PROCESS: SPECIALISED TRAINING IN ADDICTIONS PREVENTION}

The first contacts with the International Consortium of Universities for Drug and Drug Demand Reduction (ICUDDR) and the Universal Prevention Curriculum (UPC) and its European Adaptation (EUPC) started in the last trimester of 2017. In December Universidade Aberta became a formal member of ICUDDR as an education provider. A specialisation training course worth 10 ECTS, aimed at prevention professionals with prior or current experience of working in the prevention field, was designed in the first months of 2018. This proposal involved some adjustments that took account of the Portuguese context and the prevention professionals' needs; specifically, the content related to pharmacology was removed and the approach was broadened to include non-substance addictions, such as gambling and technology-related addictions.

In February 2018, a 'formal settlement of cooperation' was signed, which made it possible to use 'HoGent@ and the UPC-Adapt consortium' as a reference in the course guide of the Specialised Training in the Prevention of Addictions. This document contains all the course information: the framework, objectives and learning outcomes, content, learning resources, work plan, and evaluation. The next step was approval by the formal bodies at UAb. It was first considered by the Department of Education and Distance Learning Coordination Council and then by the UAb' Scientific Council. The course had the status of a non-formal training course, meaning that it was a professional and lifelong learning opportunity, with certification at the end, but no degree. For this reason, there was no need for it to be approved by authorities other than the internal UAb bodies. The Specialised Training in the Prevention of Addictions course was formally approved at the end of March. In early April the pedagogical design of the course began to be prepared. The provision of information on the study programme and enrolment started at the same time.

At this point there is a training need with public identification and recognition for prevention professionals and other related professionals in Portugal (SICAD, 2013) and an international network that developed the EUPC which could be adjusted to the Portuguese context and to online delivery. This was the context for the design of the first e-learning-based EUPC programme in Portuguese. The Specialised Training in the Prevention of Addictions course commenced on $4^{\text {th }}$ May.

It is intended for graduates from the social studies field who wish to broaden their qualifications or are interested in the area of health education, in particular in the field of the prevention of addiction and dependency. These include, in particular, the coordinators of prevention programmes and professionals working in prevention, as well as other professionals such as social educators, social workers, and education practitioners. This training programme has a curricular 
structure adapted (and translated) from the EUPC - European Universal Prevention Curriculum ( $\left.{ }^{\circ} \mathrm{HoGent}\right)$. Its structure features five topics preceded by an introduction to the virtual learning environment which is offered to all UAb students and is free of charge but mandatory. This introductory module aims to provide students with guidance to the virtual teaching and learning environment and to enable them to acquire the online communication skills and social skills necessary to build a virtual learning community. After the initial module has been completed, the first topic is 'Lifestyle Decisions and Prevention', which places prevention in the field of health education and the promotion of healthy lifestyles, conceptually exploiting evidence-based prevention. It also addresses the role of prevention professionals - Advocacy - and specific ethical issues pertaining to these professionals. The second topic is 'Epidemiology and Etiology', which is based on a general contextualisation of psychoactive substance use in Europe. In Portugal, it has been extended to include gambling (a game where something in the anticipated outcome is risky, which may lie at the origin of the development of addictive behaviours). Etiology models are relevant in this context for the identification of factors or mechanisms associated with addictions.

The third topic is 'Prevention Science', in which the main theories used in evidence-based prevention are discussed. This theoretical framework is fundamental for the trainees to understand the core elements needed for the development of preventive interventions. This is complemented by the study of international standards for prevention, European standards for quality prevention, and customised programmes in health education. The fourth topic, 'Monitoring and Evaluation', addresses several types of screening research that can be used to monitor or evaluate preventive interventions. The issue of collaborative work with evaluation teams and research institutions, as well as the formation of communities of practice, will also be addressed. The last module deals with 'Models of Applied Prevention'. Prevention models applied to different groups and contexts, namely the family, school, work contexts, community, environment, and the media, are presented. For each of them, specific issues and challenges related to health education and prevention will be dealt with. The focus of this approach is based on evidence-based practices.

After completing the modules, each student must carry out a theoretical and/or practical prevention-related project. The development of this project will be accompanied by the coordinator of the course. The linkage between the modules reflects the simultaneous operation of some contents that, in this way, are reinforced. Such a form of organisation also enhances the general flexibility of the training (according to the UAb Pedagogical Virtual Model ${ }^{\circ}$, which is explained in the next section. Specialised staff perform continuous monitoring of the training process and activities. With regard to such a training programme, this approach is practicable because it allows a certain amount of flexibility in terms of continuous improvement. It is an important feature, as this was the first online prevention course under ICUDDR - the International Consortium of Universities for Drug Demand Reduction.

\section{DISCUSSION - E-LEARNING AND DISTANCE LEARNING EDUCATION}

The domain of 'internet-based learning' is relatively recent and so it still needs further research, theoretical development, and conceptual stabilisation. E-learning is generally associated with technological rationality linked with the technological dimension of the artefacts that mediate learning processes (Shank \& Sitze, 2004; Guri-Rosenblith, 2005; Marquès, 2006). Distance Learning and Education is associated with the idea of de-territorialisation of the learning processes and focusing on their interaction scenarios (Hiltz \& Turoff, 2005; Downes, 2014). The important feature is that the technological innovation must be complemented with pedagogical strategies that are also innovative. At the intersection of technology and pedagogy, new learning and teaching strategies emerge. "E-learning is progressing from the basic use of ICT [Information and Communication Technologies] for learning to new forms of education and training which emphasise creativity and collaboration and new skill requirements for the knowledge society. This, in turn, requires a significant change of emphasis, away from a focus on technology, connectivity and Internet, towards a greater consideration of the context of learning, and of the need for collaboration, communication and innovation" (Penna \& Stara, 2018:5).

Distance Learning and Education provides consistent and worldwide training, reduces delivery cycle time, increases the learner's convenience, reduces information overload, improves tracking, and lowers expenses (Welsh, Wanberg, Brown, \& Simmering, 2003). And these are some of the features that help to provide an understanding of the worldwide growth of Distance Learning and Education.

Established in 1988, Universidade Aberta is the only public distance education university in Portugal. Because of its purpose, UAb uses the most advanced technologies and methods of Distance Learning, without geographical borders or physical barriers, in its teaching activities while placing special emphasis on the expansion of the Portuguese language and culture within the Lusophone world (migrant communities and Portuguese-speaking countries). All the teaching and learning activities, in both formal and non-formal training opportunities, follow the guidelines established in the Virtual Pedagogical Model ${ }^{\circ}$ (MPV). This MPV $^{\bullet}$ was specifically created for online teaching and learning at UAb and is recognised and validated by the international professional community. Within this $\mathrm{MPV}^{\circ}$, the teaching and learning activities proceed asynchronously using the UAb eLearning platform and other digital environments and online tools. The MPV ${ }^{\bullet}$ has four main principles: i) student-centred learning, ii) education based on the flexibility of access to learning, iii) education based on diversified interaction, and iv) education that promotes digital inclusion (Mendes et al., 2018; Pereira et al., 2007).

The evaluation of the implementation focused on all the aspects of the course: content, pedagogical resources and strategies, and the expertise and experience of staff and 
trainees. The diagram below outlines these aspects and their dynamic interaction (Figure 1). The content was developed around five themes (already described above). The pedagogical design of the course combined learning resources (EUPC, articles from scientific journals, videos, and official web pages such as those of the EMCDDA), e-activities (debates in forum, and collaborative work) and technologies (to support drawing a conceptual map, and to support a debate based on the 'pros and cons' approach). As the $\mathrm{MPV}^{\circ}$ has an interactive and collaborative background, the participants are integrated into a community of learning and practice which values their work experience and previous knowledge. For this same reason the staff selected for the specialised training course had great expertise. All the process was closely and constantly monitored as EMCDDA staff with proficiency in Portuguese had access to the training course and followed the development of the e-activities and the interaction within the virtual community. (Figure 1.)

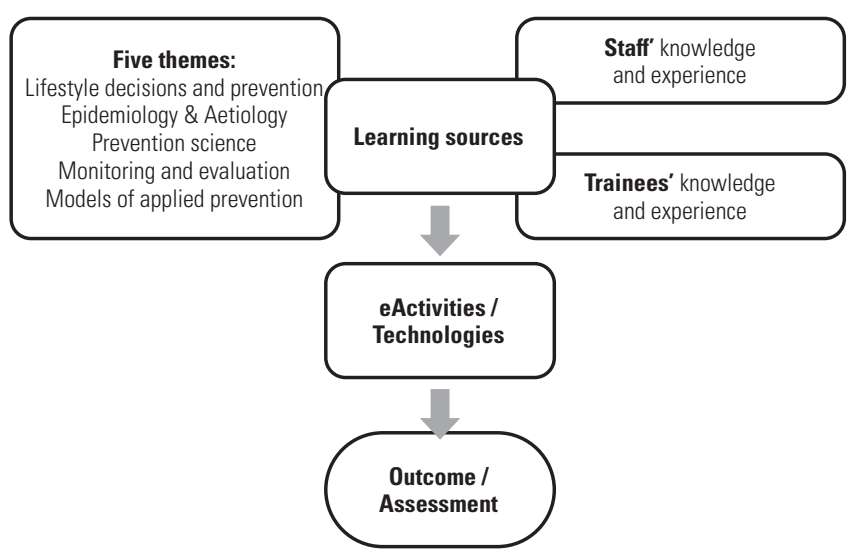

Figure 1 | Specialised training in the course in the prevention of addictions structure of the evaluation

\subsection{Difficulties and perspectives}

Ten prevention professionals participated in the training course. All of them had prevention experience, and yet this was the first specialised training in prevention. Their scientific background was very diverse, from social work to arts, psychology, and pedagogy.

Enrolment has been difficult, probably for three reasons: i) people tend to believe that they know everything about prevention, ii) the prevention of substance use might be too narrow a field, and iii) there is no perceived need for a specific formal qualification in order to do prevention work in Portugal. Only seven trainees completed the course successfully.

This evaluation highlighted some difficulties. Besides those related to enrolment (mentioned above), we face language barrier difficulties, as most of the resources are in English. For this reason, it is necessary to invest in the translation and adaptation of the EUPC to Portuguese. There is also no Portuguese-speaking scientific journal dedicated to prevention, which helps to explain the lack of scientific resources to support the content and the teaching and learning activities.

Some possibilities for the further development of online training opportunities in Portuguese were also discussed in order to truly meet the needs of prevention professionals working in Portuguese-speaking settings. The current Portuguese context and development processes, as well as prevention-specific gaps in institutional infrastructure (e.g. professional society, sufficient number of real working positions in prevention in schools and in the community, etc.), were addressed.

\section{CONCLUSIONS}

In spite of the facts that prevention is still not recognised as a unique field and the lack of a systematic approach to supporting the workforce and developing high-quality and adequate training and education programmes can be identified across European countries, we can observe the process of the first university-based training and education programmes specialising in the prevention of addictions being developed. This priority is supported by some international bodies, such as the EUSPR (European Society of Prevention Research), SPR (Society for Prevention Research), the WHO (World Health Organisation), CICAD (the Inter-American Drug Abuse Control Commission), the INL (Bureau of International Narcotics and Law Enforcement Affairs), the ISSUP (International Society of Substance Use Professionals), and just recently also ICUDDR (the International Consortium of Universities on Drug Demand Reduction). The process, facilitated by the wider international community, is accelerating and new specialised university programmes are emerging around the world. The course that was evaluated and implemented in Portugal represents the first real university-based e-learning adaptation running in a standard regime in Europe, and Universidade Aberta (Portugal) has joined Charles University (Prague) in making effective use of programmes and materials based on the original UPC curricula in the university context and supporting the idea of greater reflection on the issue of quality in education and training, specifically in the prevention of addictions. The first comprehensive university-level study programmes (e.g. the Prague model of addictology) and, in particular, courses/training that are viable and useful for different programmes that already exist, such as psychology, pedagogy, social work etc. (e.g. the Lisbon training concept) are the best ways of improving the competences of the prevention workforce and enhancing awareness among the wider professional community. 
Authors' contribution: Susana Henriques created the design, organised the collection of the data, evaluated the field reports and observations, and processed the outcomes and materials for the article. Gregor Burkhart cooperated on writing and the final version of the article. Michal Miovský cooperated on writing and the final version of the article. The authors contributed to the creation of the article and approved the final version of the manuscript.
Declaration of interest: No conflict of interest.

Penna, M. P., \& Stara, V. (2018). Approaches to E-learning quality assessment. Retrieved from https://www.researchgate.net/publication/228588294_ Approaches_to_E-Learning_Quality_Assessment_03.12.2018 - 12:12)

SICAD - Serviço de Intervenção nos Comportamentos Aditivos e nas Dependências. http://www.sicad.pt/EN/Paginas/default.aspx (06.06.2018 - 10:02)

SICAD - Serviço de Intervenção nos Comportamentos Aditivos e nas Dependências (2013). Plano Nacional para a Redução dos Comportamentos Aditivos e das Dependências 2013-2020, Lisboa: SICAD.

Shank, P., \& Sitze, A. (2004). Making sense of online learning: A guide for beginners and the truly skeptical. San Francisco, CA: Pfeiffer. D. A., \& Shek, D. T. L. L. (2012). Worldwide application of prevention science in adolescent health. Lancet, 379(9826), 1653-1664.

https://doi.org/10.1016/S0140-6736(12)60238-4

Charvát, M., Jurystová, L., \& Miovský, M. (2012). Four-level model of qualifications for the practitioners of the primary prevention of risk behaviour in the school system. Adiktologie, (12)3, 190-211.

Council of the European Union. Council conclusions on the implementation of the EU Action Plan on Drugs 2013-2016 regarding minimum quality standards in drug demand reduction in the European Union (2015). Brussels: Council of the European Union.

European Union drugs strategy (2013-2020). http://www.emcdda.europa.eu/ topics/pods/eu-drugs-strategy-2013-20_en_03.12.2018-11:05)

Guri-Rosenblith, S. (2005). 'Distance education' and 'e-learning': Not the same thing. Higher Education, 49(4), 467-493. Doi: 10.1007/s10734-004-0040-0

Hiltz, S. R., \& Turoff, M. (2005). Education goes digital: The evolution of online learning and the revolution in higher education. Communications of the ACM, 48 (10), 59-64, Doi: 10.1145/1089107.1089139.

Marquès, P. (2006). Definición del e-learning. Retrieved from www.pangea.org/peremarques (17.06.2008 - 10:32)

Mendes, A., Bastos, G., Amante, L., Aires, L. L., \& Cardoso, T. (2018). Modelo Pedagógico Virtual. Cenários de desenvolvimento. Lisboa: Universidade Aberta.

Miles, M. B., \& Huberman, A. M. (1994). Qualitative data analysis: An expanded sourcebook. London: Thousand Oaks, New Delhi: SAGE Publications.

Miovský, M., Gabrhelík, R., Libra, J., Popov, P., Pavlovská, A., Kalina, K., et al. (2016). The Prague Comprehensive Model of Academic Addictology (Addiction Science) Education. Adiktologie, 16(1), 36-49.

National Plan for Reducing Addictive Behaviours and Dependencies (2013-2020). http://www.sicad.pt/PT/Institucional/Coordenacao/Paginas/default.aspx

(09.11.2013-09:25)

Ostaszewski, K., Feric Slehan, M., Foxcroft, D. R., Kosir, M., Kranzelic-Tavra, V. Mihic, J., ... Talic, S. (2018). European Prevention Workforce Competences and Training Needs: an Exploratory Study. Adiktologie, 18(1), 7-15.

Pavlovská, A., Pavlovská, A., Miovský, M., Babor, T. F., \& Gabrhelík, R. (2017). Overview of the European university-based study programmes in the addictions field. Drugs: Education, Prevention and Policy, 24(6), 485-491. doi: $10.1080 / 09687637.2016 .1223603$

Patton, M. Q. (1990). Qualitative evaluation and research methods. London, Thousand Oaks, New Delhi: SAGE Publications.
Universidade Aberta, http://portal.uab.pt/en/auab/ (06.06.2018 - 10:09)

Welsh, E. T., Wanberg, C. R., Brown, K. G., \& Simmering, M. J. (2003).

E-learning: emerging uses, empirical results and future direction. International Journal of Training and Development, 744), 245-258. doi: 10.1046/j.1360-3736.2003.00184.x

WHO (2000a). International Guidelines for the evaluation of treatment services and systems for psychoactive substance use disorders. Geneva: WHO/UNDCP/EMCDDA.

WHO (2000b). Process Evaluations. Workbook No. 4. Geneva: WHO/UNDCP/EMCDDA. 